\title{
MANAGEMENT OF MOTIVATION OF MANAGERS' WORK AT THE ENTERPRISES OF UKRAINE: INNOVATIVE ASPECTS
}

\author{
Iryna POPADINETS \\ Vasyl Stefanyk Precarpathian National University \\ Uliana ANDRUSIV \\ Ivano-Frankivsk National Technical University Oil and Gas \\ Olga GALTSOVA \\ Classical Private University, Zaporizhzhia \\ Mariia BAHORKA, Natalia YURCHENKO \\ Dnipro State Agrarian and Economics University
}

\begin{abstract}
:
The purpose of the paper is to develop a model for managing the motivation of managers and ensure its effectiveness. The principles of formation of management model of managers' work motivation which correspond to the universal system approach to management model of managers' work motivation and define its basic functions are outlined: a) goal setting, b) assessment and forecasting of the state and efficiency, c) development and decision making, d) planning, e) organizational, f) communication and subordination, g) regulation of the management model of motivation of managers, h) control. The management model of managers' work motivation of (MMMWM) is formalized in the form of a structural-logical scheme based on a systematic approach and decomposition, which reflects the interaction of subject and object in the process of forming and implementing a system of motivation of managers at the enterprise. The factors for achieving the set goals have been formed, which are divided into internal and external motivators for managing managers' work motivation. The management model of managers' work motivation which is presented by the following subsystems is offered: " $X$ " - target subsystem (the management process of managers' work motivation), " $Y$ " - providing subsystem (factors of rational achievement of the goals), "XY" - providing subsystem (regulatory legal acts, resources), "Z" - management subsystem (reflects the implementation of the general functions of management work motivation on the basis of experience), which are characterized by parameters, indicators, criteria for managing the motivation of managers. According to the method of linear multiple regression, a system of equations was constructed to describe the economic-mathematical model of management motivation at oil and gas enterprises, which after the repeated experiments provided diagnostics of indicators before, during and after the implementation of management motivation model.
\end{abstract}

Key words: motivation, management model, managers' work, enterprise

\section{INTRODUCTION}

The results of modern enterprises functioning are determined by the quality of management, which is ensured by the efficiency of managerial staff. In recent years, there has been a shortage of professional and experienced managers at all levels of management of oil and gas companies, due to which these companies can not develop, and their activities are unprofitable. We can clearly trace the ineffectiveness of outdated policies and methods of motivation, changes in the age structure of senior and middle management, changes in motivation priorities, which, in turn, requires the construction of a new model of managing the motivation of managers at oil and gas enterprises.

The main impetus for motivating managerial staff at all levels is a comprehensive systematic approach to motivating managers, which ensures the involvement of competent managers, retention of valuable managers, stimulating the effectiveness of management at a reasonable level of costs. 


\section{LITERATURE REVIEW}

In the event of a protracted crisis of enterprises, an important and urgent problem is the development of theoretical and practical recommendations for the formation of a model for managing the motivation of managers in oil and gas companies, which will justify and implement a comprehensive system approach to motivating managers. The issues of developing the theoretical foundations of management motivation have been studied in the works of domestic and foreign scholars, in particular: Smirnova [1] and Kinash [2] argue that the motivation of managerial staff is of particular importance, because the results of the enterprise's activity depend directly on the effectiveness of the management decisions. Gunduz [3] identified factors that have an important impact on the motivation of senior employees, namely: the most important issues are the exchange of technical experience with partners and the management of partner relations. Dogar [4] says that the psychological climate in an organization has a significant impact on motivation of its employees. Lorincová [5] proves that properly motivated managers direct their efficiency to influence business efficiency and, consequently, the success and sustainability of the enterprise. After all, the efficiency of the enterprise depends on effective management and business processes carried out by them Cherchata [6]. Bryson [7] in their work consider the internal job satisfaction and organizational commitment of employees as motivational results. The authors argue that the returns on small business investment in HRM are U-shaped. Kampf [8] consider various factors that have an impact on the motivation of managerial work and conclude that the enterprise development strategy should include a program of employee motivation. Kampf [9] identified significant differences between the needs of senior management and blue-collar workers using the Student's t-test and saw that in the field of motivational factors in Slovakia it is impossible to create a single motivation program for the analysed groups of workers. Mikkelsen [10] emphasize that the internal motivation of the employees depends on the need of employees for self-determination. Hitka [11] analysed the level of motivation of employees in V4 countries and based on the questionnaire identified the most important motivating factors wages, a good workforce, a positive working atmosphere and comfortable working conditions. Pakovska [12] argue that the productivity of managers depends on knowledge, working conditions and their motivation to work. The motivation of a manager depends on the incentives that are present in the individual environment or used by other people to achieve the desired changes in human behavior. Du [13] argues that due to human resources, motivation becomes a key factor in the realization of human resource potential. Scientists levdokymov [14], agree with this statement and prove that it is the person and his personal motivating values that determine the effectiveness and efficiency of the enterprise. Panagiotakopoulos [15] examined employee motivation during the financial crisis at Greek enterprises and found that it is the psychological climate that plays the most important role in employee motivation. In order for enterprises to be effective, they need to have effective managers, because their innovative decisions and actions will determine the effectiveness of the enterprise, and as a consequence, the welfare of the country, Andrusiv [16]. Polyanska [17] and Dykha [18] argue that it is necessary to work on the development of corporate culture of the enterprise. This will help build trust between employees and top managers and develop young executives. Khytrova [19] in their study proved that the timely detection and diagnosis of problematic situations that arise in the development and growth of enterprises and organizations, significantly depends on the level of qualification and professionalism of the leader. Scientists from Greece [20] analyzed the relationship between leadership styles used by managers and their motivation, which motivates them to achieve their goals. Then, with the help of Herzberg's two-factor model, the motivational influence on a specific leadership style was determined. In their work, Paglis researchers [21] explore the self-efficacy of leadership and the motivation of managers to change. It is established that top managers are the most motivated and respond best to change. Mast [22] in their work proved that the effectiveness of leadership is influenced by the motivation of senior management. Wziatek-Staśko [23] substantiated the importance of motivating managers as a determining factor in the quality of management. Scientists [24, 25] conducted a comparative analysis of the level of employee motivation at small and medium-sized enterprises in Russia and the United States. They found that there is a gap between the two, as the United States has a stable and free market economy, has a strong entrepreneurial culture, and the small business sector plays an important role in the economy. The survey showed that much attention is paid to the level of work motivation of managers in the United States, since the success of the enterprise depends on their competence. The differences have arisen from less developed business infrastructure in Russia versus the United States, an unstable business environment in Russia versus stability in the United States, and finally cultural differences.

However, many issues related to the formation of a model for managing the motivation of managers of oil and gas companies remain unclear. Thorough research is required to develop a system of indicators to assess the level of effectiveness of managerial work motivation, to develop a model of managing the motivation of managers and as well as to formalize it.

The paper aims at developing a model for managing the motivation of managers and ensuring its effectiveness.

\section{METHODOLOGY}

To achieve this goal, the following research methods were used in the work:

- theoretical generalization - for a more in-depth study of the motivation of managers;

- graphic - to build a model of managing the motivation of managers;

- system approach - in the construction of the target, providing and management subsystem of motivation of managers; 
- analysis and comparison - for analytical procedures for evaluating management subsystems, their testing on the example of oil and gas companies;

- economic-mathematical method (linear multiple regression) - to build a system of equations to describe the economic-mathematical model of management motivation of managerial work in oil and gas companies.

The classification method was used to determine factors and form constraints on the motivation of managers; the sociological method (questionnaire survey) was used in the collection and analysis of data on the motivation and performance of managers in the surveyed enterprises; methods of information technology (expert systems) was applied when conducting expert consultations on the assessment of the existing model of work motivation for managers (for the reliability of the result, the assessments of 10 experts were used and the results obtained were rendered into points:

1 point - low level,

2 points - medium level,

3 points - high level), the expert method was used to obtain results on the adequacy of the managerial work motivation model on the example of oil and gas enterprises (the study was carried out in 3 stages: before the implementation of the managerial work motivation model (experiment $1(Z)$ ), during the implementation of the managerial work management model (experiment $\left.2\left(Z^{\prime}\right)\right)$ and the final study (experiment $3(Z$ "))) stepwise regression method to establish the influence of factors on the functional.

\section{RESULTS}

The formation of market relations, globalization and the deep transformation of industrial society into information (post-industrial) one, where the main role should be played by knowledge, intelligence, and innovation Popadynets [26] and Andrusiv [27] necessitate the formation of a systematic approach to motivation of managerial work. Today, human development is the main dimension and lever of social progress, therefore its condition in the near future will determine the effectiveness of socio-economic motivation in the field of labor and competitiveness of enterprises and the economy as a whole, Zelinska [28]. The formation of a model for managing the motivation of managers should begin with the definition of the principles of its construction, which should include the following:

1) systematicity, which provides for the construction of a model for managing the motivation of managers as an organizing and providing system for the formation and regulation of the development of managerial work motivation;

2) goal orientation - formation of a multilevel system of goals that eliminates threats through the coordination of interests and needs of different parties;

3) stimulation involves the achievement of individual goals through collective and interest in the results through the tools of stimulation;
4) continuity of development - is the creation of conditions for achieving continuity and efficiency of improving the motivation of managerial work at the enterprise;

5) reliability - involves a balance of methods, levers, tools and forms of motivation of managers through the formation of constant and variable parts of payment and material incentives for managerial staff;

6) unity of action - is to ensure the interaction of all elements and components as a whole system;

7) elasticity - is to ensure the timeliness of response to external and internal changes and disturbances through motivational monitoring and control;

8) innovativeness - the focus on the use of advanced methods, modern forms, management technologies and motivation of managers;

9) resource security - is the optimal use of resource potential of the enterprise;

10) cost-effectiveness - involves the formation of resources for incentives, based on its effectiveness (implementation costs may not exceed the economic effect of the implemented measures);

11) complexity - is to ensure the full use of constraints, opportunities and motives to determine the system of incentives and develop on its basis a program of measures to improve the motivation of managers;

12) balance of interests - taking into account the interests of economic entities with which the company interacts, and the motives of managers at all levels through a system of goals and defining the objectives of the model based on it.

The described principles correspond to the universal system approach to the model of management of managers' work motivation and define its basic functions. According to the results of the study, the functions of the model of managing the motivation of managers include:

1) goal setting, which regulates the continuity of the goals of the model of managing the motivation of managers in accordance with the purpose, strategy, constraints, opportunities and motives;

2) assessment and forecasting of the state and effectiveness of motivation of managerial work;

3) development and decision-making on management and implementation of measures in the conditions of external and internal threats (choice of forms, methods, levers, tools, etc.);

4) planning: defining tasks, formation of a system of incentives, substantiation of the program of measures for improvement of management and managers' work motivation;

5) organizational - procedural formalization of the process of making and ensuring the implementation of decisions to manage the motivation of managers;

6) communication and subordination - involves the coordination of actions and interaction of elements of the management model of managers' work motivation; 
7) regulation of the functioning of the management model of managers' work motivation and its components - provides for the implementation of measures through timely adjustment, change and improvement of tools for managing work motivation to ensure the implementation of tasks and goals;

8) control of deviations in the process of implementation of measures from the level of planned indicators, criteria, parameters and goals of development of the management model of managers' work motivation.

The visualization of the MMMWM model using the structural logic diagram is carried out in Fig. 1. This model reflects the interaction of a subject and an object in the process of formation and implementation of the system of motivation for managerial work at the enterprise. According to the above theoretical and analytical scheme, management model of managers' work motivation includes motivational, organizational, security and functional components that characterize the formation of a system of remuneration and motivation for managerial work, the implementation and control of the effectiveness of the implementation of the latter at the enterprise.

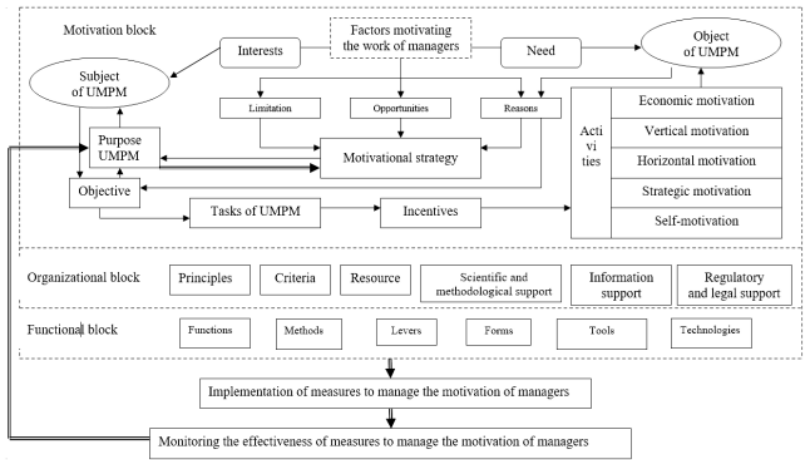

Fig. 1 Structural and logical scheme of the management model of managers' work motivation

The effectiveness of the management model of managers' motivation depends on a holistic approach. After all, a new paradigm of scientific thinking, a holistic system, is characterized by the following changes in relation to traditions: the transition from "part" to the whole, integrity; from "structure" to "process" [26].

Motivation of managerial work, like any complex model, requires control and management. Management of motivation of managerial work is a process of planning and organization of motivation of managerial work, studying of its development in time, control and regulation over its implementation. Therefore, we offer an author's model of managing the motivation of managers based on a system approach (XYZ-models).

Our proposed model of management motivation of managerial work is represented by the

following subsystems: " $X$ " - target subsystem, "Y" - support subsystem, "XY" - regulatory subsystem, "Z" - control subsystem, which can be evaluated by parameters, indicators, and criteria of management of managers' work motivation (Fig. 2).

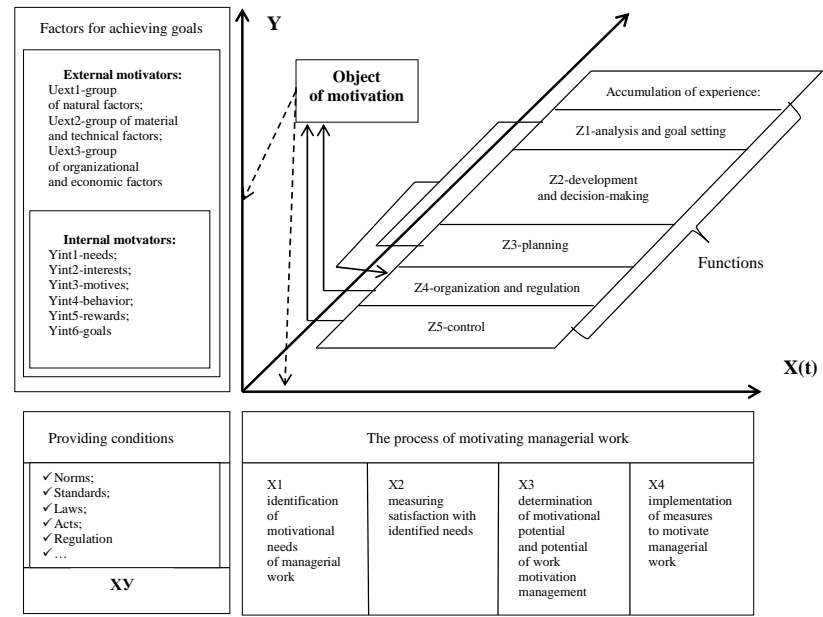

Fig. 2 Management model of managers' work motivation

Target subsystem " $X$ " (the process of motivating managerial work) illustrates the management cycle (set of stages, processes, functions that must be performed to achieve the goal (result). The implementation of goals and processes that must be carried out to form the motivation of managerial work, determine the factors of achieving goals, which we divided into external and internal motivators (subsystem "Y").

External motivators are generalized into three groups: natural factors, material and technical factors and organizational and legal factors; and internal factors are divided into five groups: needs, interests, motives, behavior, rewards, and goals.

The management subsystem ("Z") reflects the implementation of the general functions of managing the motivation of managers against the background of experience and is aimed at achieving results. Such a system of relations requires improvement and stabilization of the system of laws, normative acts, instructions, orders, i.e. the entire regulatory framework (subsystem "XY").

Let us consider in detail each axis and its components. The " $X$ " axis is the target subsystem: the process of motivating managerial work. This subsystem is represented by the following components:

X1 - identification of motivational needs of managerial work,

$\mathrm{X} 2$ - measurement of satisfaction with identified needs, X3-determination of motivational potential and management potential of work motivation,

X4 - implementation of management motivation measures.

To implement the model of managing the motivation of managers, the factors of achieving the set goals (axis " $Y "$ ) are determined. We detail the factors that are divided into internal and external motivators of managers' work motivation. External motivators include (Table 1): Uz1group of natural factors; Uz2-group of material and technical factors; Uz3-group of organizational and economic factors. 
Socio-economic conditions (duration of working hours and working year, payment and incentives, qualification, professional and general training of employees)

Factors

Sanitary and hygienic conditions (temperature, gassiness, dust, air pollution, lighting, noise, vibration, etc.)

1 of satisfaction with working conditions

Organizational conditions (working hours, provision of materials, raw materials and tools)

Social and living conditions (providing employees with living quarters, canteens, medical and sanatorium services, etc.)

Average and minimum wages

2 Factors of satisfaction with the level of wages Average and minimum pension

Average cash aid, etc.

Psychophysiological and personal characteristics of team members, features of their temperaments, characters, needs, etc.

Socio-psychological features of the team: moral climate, cohesion, readiness for work, discipline, etc.

3 Factors of satisfaction with management style

Psychophysiological and personal qualities of the team leader. The manager combines all the objective, external influences that reflect the characteristics of the team led by him. Through them, the management style is formed whis is as unique as the unique personality of the manager.

The competence of the manager is the quality of his personality, which helps to consciously develop the most rational style of management based on experience, scientific and general cultural outlook.

Awareness of the manager with the features of the team he manages, helps him to choose a style that meets the specific conditions in which the team and its leader

Factors of the level

of emotional

4 atmosphere

System of interpersonal relations (sympathy, antipathy, friendship)

Psychological mechanisms of interaction between people (imitation, empathy, assistance)

in the team

System of mutual requirements, general mood, general style of joint work activity, intellectual, emotional and volitional unity of the team

Satisfaction of workers with job in general and its individual elements (physical activity, condition of equipment, organization of work, safety, significance of products, content of work, work in general) Indices of indicators of attitude to work (degree of completion of shift tasks, labor discipline, degree of labor efficiency, degree of activity in professional development, responsibility for the use of working time)

5 Factors of job

Hierarchy of the most significant motives that determine the overall job satisfaction (prospects for training, earnings, condition of equipment)

Indicators of attitude to work and assessment of elements of the production situation (the degree of labor efficiency, the degree of activity in improving their skills, the degree of performance of variable tasks)

Internal motivators are (Table 2):

Uvn1 - needs;

Uvn2 - interests;

Uvn3 - motives;

Uvn4 - behavior:

Uvn5 - rewards;

Uvn6m - goals.

A properly organized motivation system is an effective management tool if it provides: coordination of managers' own goals with the goals of the organization and staff; reduction of costs for search, selection and adaptation of management staff; maintenance of highly qualified specialists; solving the most important problems of personnel management.
The management system ("Z" axis) reflects the implementation of the general functions of the management model of the motivation of managers. We detail them:

$\mathrm{Z1} \mathrm{-} \mathrm{definition} \mathrm{of} \mathrm{goals} \mathrm{and} \mathrm{analysis} \mathrm{of} \mathrm{the} \mathrm{system} \mathrm{of} \mathrm{mo-}$ tivation of managerial work,

Z2 - development and decision-making,

Z3 - planning of motivation of managerial work,

$\mathrm{Z} 4$ - organization and regulation of motivation of managerial work, Z5 - control as a tool of motivation of managerial work. 
Table 2

Internal factors of management of managers' motivation

\begin{tabular}{ll}
\hline $\begin{array}{l}\text { Component } \\
\text { of the model }\end{array}$ & \multicolumn{1}{c}{ Management } \\
levels
\end{tabular}

Regarding the subsystem "XY", it represents the entire regulatory framework that allows one to form and implement a model of managing the motivation of managers. Mathematical modeling was used to describe the management model of managers' work motivation, which allows to obtain a simplified, abstract, formally described model. The latter covers a class of indeterminate parameters or vectors, the interaction and relationship between them, which can be described by mathematical operations.

One of the effective methods of modeling is multiple linear regression, which is described by a system of linear equations:

$$
\begin{gathered}
\left(\begin{array}{c}
y_{1} \\
\vdots \\
y_{n}
\end{array}\right)=\left(\begin{array}{ccc}
f_{1}\left(x_{1}\right) & \cdots & f_{p}\left(x_{1}\right) \\
\vdots & \ddots & \vdots \\
f_{1}\left(x_{n}\right) & \cdots & f_{p}\left(x_{n}\right)
\end{array}\right)\left(\begin{array}{c}
\beta_{1} \\
\vdots \\
\beta_{p}
\end{array}\right)+\left(\begin{array}{c}
\varepsilon_{1} \\
\vdots \\
\varepsilon_{n}
\end{array}\right) \\
\bar{y}=\overline{\ldots X} \bar{\beta}+\bar{\varepsilon}+\bar{\varepsilon}
\end{gathered}
$$

The linear regression model contains a set of outputs $Y n$ in the form of a linear combination of model terms $F(X) \cdot \beta_{j}$ $(J=1, \ldots, p)$ in each of the observations $(x 1, y 1), \ldots$, (xn, yn).

If the input $x$ is multidimensional, then the functions $F$ form a group of models. For example, if the input $x=(x 1, x 2)$, the conditions for the model may include $f 1(x 1)=x 1$ (linear term), $f 2(x 1)=x 12$ (square term), and $f 3(x)=x 1 \times 2$ (pairwise interaction). Typically, the function $f(x)=1$ is included in the number $f j$, so that the matrix $X$ contains column 1 and the model contains a constant component.

Linear regression models are used for:

- establishment of factors of the greatest influence on model outputs (coefficients $\beta_{\mathrm{j}}$ with the greatest value);

- determining the direction of influence (features of $\beta_{\mathrm{j}}$ );

- forecasting the response value $(y(x)$ for the new $x)$.
The Statistics Toolbox regress and regstats functions are used to find multiple linear regression coefficients.

The analysis of factors influencing the motivation of managerial work is carried out using step-by-step multiple linear regression, building several linear regression models, given the potentially large number of conditions. The number of members of the interaction, for example, increases exponentially with the number of predictors. If there is no theoretical basis for choosing the shape of the model, and there is no assessment of the correlation between conditions, one can include backup conditions in the model, which mix the identification of significant effects.

At the first stage of diagnosis of management motivation, namely the identification of motivational needs, a number of factors, including internal motivators (needs, interests, motives, behavior, rewards and goals) have a significant influence. When applying the stepwise regression method, it was found that a number of factors do not have a significant impact on the functionality at this stage, among them: interests, motives, rewards and goals. These factors received negative indicators in the calculations. The quality of this dependence is $89 \%$, as R-square = 0.8901 .

The second stage is characterized by the influence of external and internal factors. Moreover, external motivators fully influence the identification of motivational needs. And among internal motivators, motives, rewards and goals have a negative impact. The quality of the relationship between the second stage of management motivation and internal and external motivators is $93 \%$, as $\mathrm{R}$ square $=0.9369$.

External motivators have a significant impact on the third stage of the process of motivating managers: measuring satisfaction with identified needs. In particular, natural and organizational-technical factors have an insignificant influence. The quality of the dependence is very low and is $2 \%$, as R-square $=0.0282$.

Measurements of satisfaction of identified needs and internal motivators are also characterized by dependence. Two factors have the greatest influence: motives and rewards. Other factors have little effect. The qualitative relationship between the satisfaction of identified needs and internal motivators is $63.27 \%$, as R-square $=0.6327$.

The last stage of diagnostics of motivation of managerial work (introduction of measures of managerial work motivation) depends on external factors, moreover, all factors do not enter into close interaction with each other and do not influence the final stage of motivation of managerial work. Qualitative dependence is negative and R-square is -4.44 .

To increase the efficiency of motivational process management it is necessary to determine the actual level of staff motivation and, if the level is insufficient, to assess the motivational sphere of employees to identify the most important motives and activate them with a help of external incentives, which should increase motivation and operating efficiency in general. 
Therefore, it is expedient in the course of formation of managers' work motivation management model at the enterprise to solve the following basic tasks:

1. To determine the level of motivation of employees of the enterprise, which will allow to draw a conclusion about the effectiveness of the current model of managing the motivation of managers and the need to increase it.

2. If the level of motivation is sufficient, it is necessary to justify the reserves for its further maintenance. Otherwise, it is necessary to assess the features of building a model of managing the motivation of managers on the basis of identified potential work motives.

3. On the basis of the formed model of management of managers' work motivation to develop a system of incentives in order to adjust it.

One of the components of the model of managing the motivation of managers is the collection of information about the internal and external environment of the object of study and analysis of the impact on the motivation of managers of its main elements.

Information about the internal environment is used to determine the internal capabilities and potential of work motivation, which can be relied on to achieve the goals of managing the motivation of managers. Analysis of the internal environment allows one to understand the goals and objectives of the organization.

The main elements of the internal environment are: production (volume, structure, nomenclature of products and types of services, availability of social infrastructure, quality control, etc.); staff (structure, qualifications, number, interests and needs of employees); management organization (organizational structure, leadership style, organizational culture, organizational communication system at the enterprise); financial indicators (financial stability and solvency of the enterprise, profitability, etc.).

The main elements of the external environment that need to be considered are the state of the labor market in this industry or in the country as a whole, the supply and demand of labor, the cost of labor.

The most difficult tasks of an effective model of managing the motivation of managers is to determine the level of motivation and evaluate the management of managers' motivation that require the development and use of appropriate methods.

The formal description of the main components of the constructed model of management of managers' work motivation is made by means of economic and mathematical model and the dependence of its components is analysed.

Management analysis and goal-setting of the model of managing the motivation of managers will relate to such a component as identifying the motivational needs of managerial work (Fig. 3).

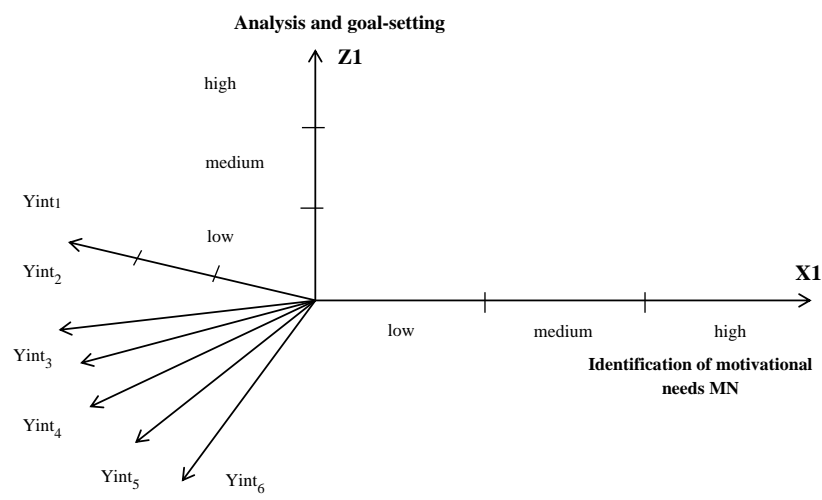

Fig. 3 Dependence of management analysis on the identification of motivational needs and internal motivators

In the process of analyzing the motivation of managerial work, it will be influenced by internal motivators, namely needs, interests, motives, behavior, rewards and goals. We present a graphical interpretation of the above.

Graphic interpretation allows to make a mathematical dependence of managerial analysis and goal-setting on the identification of motivational needs of managerial work and internal motivators.

$$
\begin{aligned}
& Z_{1}=a_{1} * X_{1}+b_{1.1} * Y \text { in }_{1.1}+b_{1.2} * y \text { int }_{1.2}+b_{1.3} * \\
& \mathrm{yint}_{1.3}+b_{1.4} * \text { y int }_{1.4}+b_{1.5} * \text { y int }_{1.5}+b_{1.6} * \\
& \text { y int } \text { i. }_{1.6}+\text { const }
\end{aligned}
$$

Let us consider the following component of the model of managing the motivation of managers i.e. development and making management decisions. This component is directly related to the determination of motivational potential under the influence of external and internal motivators. Let us consider a graphical interpretation (Fig. 4).

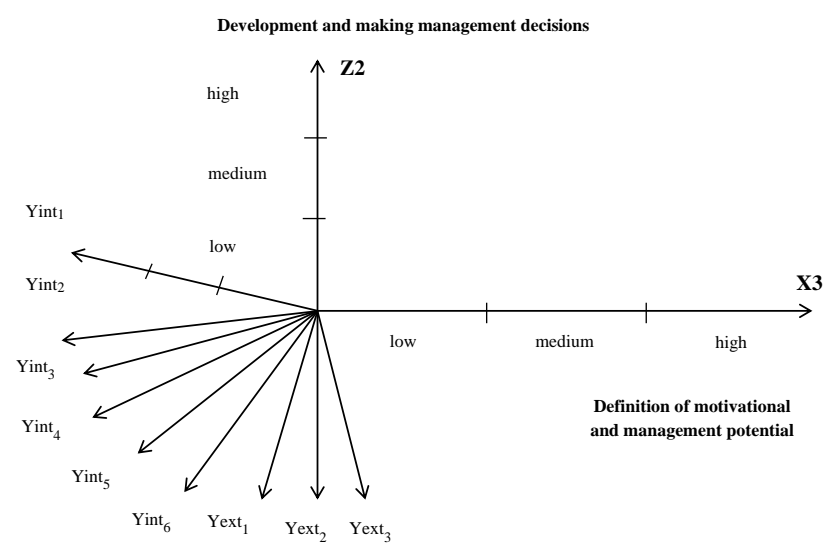

Fig. 4 Dependence of development and making administrative decisions on definition of motivational potential and management potential of managers' work motivation as well as internal and external motivators

Graphic interpretation makes it possible to build a mathematical dependence of the development and making management decisions on the definition of motivational potential and the potential of managing the motivation of managers.

$$
\begin{aligned}
& Z_{2}=a_{2} * X_{3}+b_{2.1} * Y \text { int }_{2.1}+b_{2.2} * Y \text { int }_{2.2}+b_{2.3} *
\end{aligned}
$$

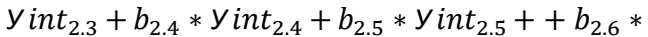

$$
\begin{aligned}
& \text { y }_{\text {int }} 2.6+b_{2.7} * \text { yext }_{2.1}+b_{2.8} * \text { yext }_{2.2}+b_{2.9} * \text { yext }_{2.3}+
\end{aligned}
$$


Let us consider the following component of the studied model of managing the motivation of managers: planning motivation of managerial work. This type of activity is used to measure satisfaction with identified needs and is influenced by external motivators. Let us consider a graphical interpretation (Fig. 5).

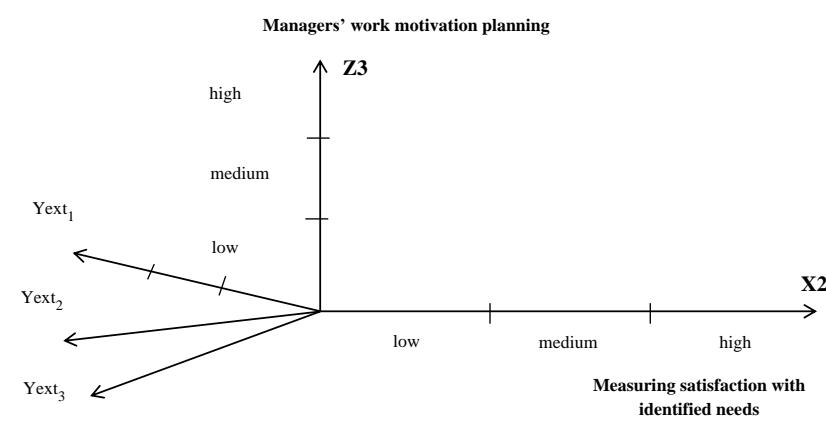

Fig. 5 Dependence of management motivation planning on measuring satisfaction with identified needs and external motivators

Graphic interpretation allows to substantiate the mathematical dependence of planning the motivation of managers' work on measuring the satisfaction of motivational needs of managerial work and internal motivators.

$$
\begin{gathered}
Z_{3}=a_{3} * X_{2}+b_{3.1} * \text { yext }_{3.1}+b_{3.2} * \text { yext }_{3.2}+b_{3.3} \\
* \text { yext }_{3.3}+\text { const }
\end{gathered}
$$

The organization and control of work motivation of managers, which also includes regulation, will be influenced by such a component of the Model of management of work motivation of managers as measuring satisfaction with identified needs under the influence of internal motivators (Fig. 6).

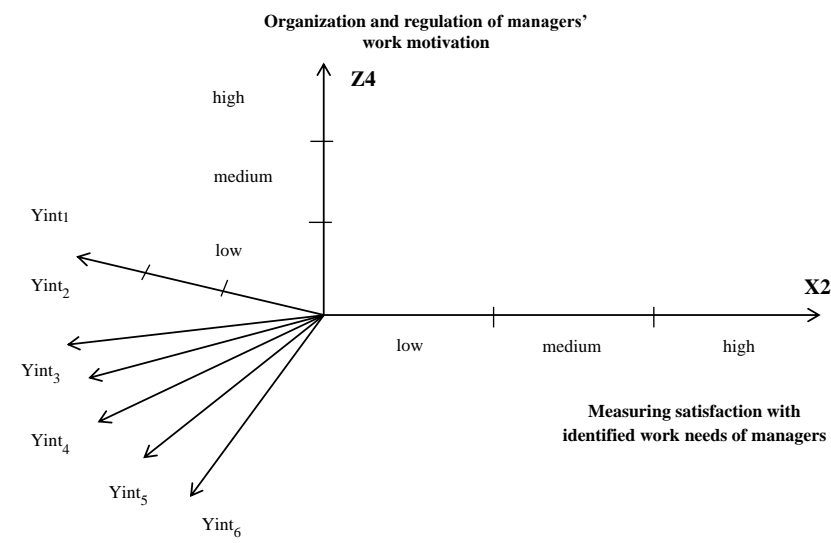

Fig. 6 Dependence of the process of organizing and regulating the motivation of managers on the measurement of satisfaction with identified needs and internal motivators

Let us present a graphical interpretation of the above. Graphic interpretation allows to make a mathematical dependence of managerial analysis on the identification of motivational needs of managerial work and internal motivators.

$$
\begin{aligned}
& Z_{4}=a_{4} * X_{2}+b_{4.1} * Y \text { in } t_{4.1}+b_{4.2} * \\
& y_{\text {int }_{4.2}}+b_{4.3} * y_{\text {int }} 4.3+b_{4.4} * \text { yint }_{4.4}+b_{4.5} * \\
& \operatorname{yint}_{4.5}++b_{4.6} * y_{\text {int }} 4.6+\text { const }
\end{aligned}
$$

The last function of the model of managing the motivation of managers is to control the motivation of managers, therefore it will be considered at the final stage of implementing measures to motivate managers and regulating the model of managing motivation of managers under the influence of external motivators (Fig. 7).

$$
Z=\oint(X, Y, X Y)
$$

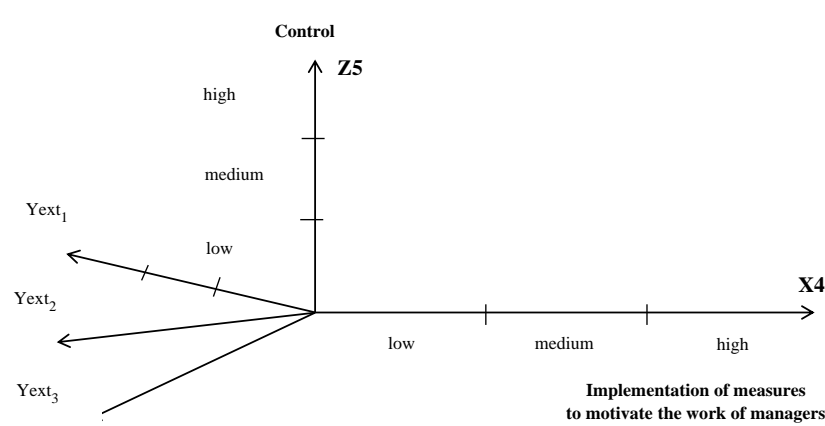

Fig. 7 Dependence of control of motivation of managerial work on introduction of measures of managers' work motivation and external motivators

Graphic interpretation makes it possible to make a mathematical dependence of management analysis on the identification of motivational needs of management work and internal motivators.

$$
\begin{gathered}
Z_{5}=a_{5} * X_{4}+b_{5.1} * \text { yext }_{5.1}+b_{5.2} * \text { yext }_{5.2}+b_{5.3} * \\
\text { yext }_{5.3}+\text { const }
\end{gathered}
$$

The method of expert estimates was used to obtain quantitative values and perform mathematical calculations. For reliability of result we will use estimation of 10 experts and we will transform the received results into points:

1 point - low level;

2 point - medium level;

3 point - high level.

Let us combine the obtained equations into a system of equations:

$$
\begin{aligned}
& Z_{1}=a_{1} * X_{1}+b_{1.1} * Y \text { int }_{1.1}+b_{1.2} * \text { yint }_{1.2}+b_{1.3} * \text { yint }_{1.3}+
\end{aligned}
$$

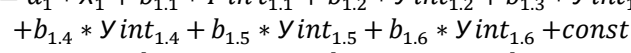

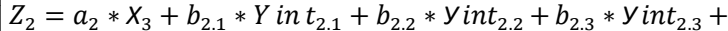

$$
\begin{aligned}
& +b_{2.4} * \text { yint }_{2.4}+b_{2.5} * y_{\text {int }_{2.5}}+b_{2.6} * y_{\text {int }_{2.6}}+ \\
& +b_{2.7} * \text { Yext }_{2.1}+b_{2.8} * \text { Yext }_{2.2}+b_{2.9} * \text { Yext }_{2.3}+\text { const } \\
& \left\{Z_{3}=a_{3} * X_{2}+b_{3.1} * \text { yext }_{3.1}+b_{3.2} * \text { yext }_{3.2}+b_{3.3} * \text { yext }_{3.3}+\right. \\
& Z_{4}=a_{4} * X_{2}+b_{4.1} * Y \text { int }_{4.1}+b_{4.2} * y_{\text {int }_{4.2}}+b_{4.3} * y_{\text {int }} 4.3+ \\
& +b_{4.4} * \text { y }_{\text {int }} 4.4+b_{4.5} * y_{\text {int }_{4.5}}+b_{4.6} * y_{\text {int }_{4.6}}+ \\
& + \text { const } \\
& Z_{5}=a_{5} * X_{4}+b_{5.1} * \operatorname{yext}_{5.1}+b_{5.2} * \operatorname{yext}_{5.2}+b_{5.3} * y_{\text {ext }} t_{5.3}+ \\
& + \text { const }
\end{aligned}
$$

To solve the system of equations, it is advisable to use a program of linear multiple regression. The study used an expert method and the study was conducted in 3 stages (Tables 3-6): before the introduction of the management motivation model (experiment $1(Z)$ ), during the implementation of the management motivation management model (experiment $2\left(Z^{\prime}\right)$ ) and the final research (experiment $\left.3\left(Z^{\prime \prime}\right)\right)$. 
Table 3

Calculation of the level of managerial analysis of the motivation of managers $\left(Z_{1}\right)$ Level of

\begin{tabular}{ccccccccc}
\hline $\begin{array}{c}\text { Model } \\
\text { coefficients }\end{array}$ & Value & $\begin{array}{c}\text { Variable } \\
\text { models }\end{array}$ & & Value & \multicolumn{4}{c}{$\begin{array}{c}\text { Level of } \\
\text { analysis and } \\
\text { goal setting }\end{array}$} \\
\hline a1 & 0.435897 & X1 & 2.6 & 1.7 & 1.7 & & & \\
b1.1 & 0.09375 & Yint1.1 & 2.4 & 1.8 & 1.7 & & & \\
b1.2 & -0.291667 & Yint1.2 & 2.3 & 2.4 & 2.2 & & & \\
b1.3 & -0.897436 & Yint1.3 & 2.2 & 2.1 & 1.7 & 1 & 1 & 2 \\
b1.4 & 0 & Yint1.4 & 2 & 1.9 & 2.4 & & & \\
b1.5 & -0.410256 & Yint1.5 & 1.9 & 1.8 & 1.9 & & & \\
b1.6 & -0.1 & Yint1.6 & 2.6 & 1.7 & 2 & & &
\end{tabular}

Table 4

Calculation of the level of development and making managerial decisions $\left(\mathrm{Z}_{2}\right)$

\begin{tabular}{|c|c|c|c|c|c|c|c|c|}
\hline \multirow[t]{2}{*}{$\begin{array}{c}\text { Model } \\
\text { coefficients }\end{array}$} & \multirow[t]{2}{*}{ Value } & \multirow[t]{2}{*}{$\begin{array}{c}\text { Variable } \\
\text { models }\end{array}$} & \multicolumn{3}{|c|}{ Value } & \multicolumn{3}{|c|}{$\begin{array}{c}\text { Level of devel- } \\
\text { opment and } \\
\text { making mana- } \\
\text { gerial decision }\end{array}$} \\
\hline & & & E1 & E2 & E3 & $\mathrm{Z}_{2}$ & $Z_{2}^{\prime}$ & $\mathrm{Z}_{2}^{\prime \prime}$ \\
\hline a2 & -0.074074 & X3 & 2.2 & 1.4 & 1.3 & & & \\
\hline b2.1 & 0.647059 & Yint2.1 & 2.2 & 1.8 & 2.1 & & & \\
\hline b2.2 & -0.453782 & Yint2.2 & 2.9 & 1.5 & 1.9 & & & \\
\hline b2.3 & 0 & Yint2.3 & 3 & 1.6 & 1.4 & & & \\
\hline b2.4 & 0.159664 & Yint2.4 & 1.9 & 1.7 & 1.9 & & & \\
\hline b2.5 & -0.097561 & Yint2.5 & 2.7 & 1.6 & 1.8 & 2 & 3 & 3 \\
\hline b2.6 & 0.0740741 & Yint2.6 & 2.6 & 2.1 & 1.6 & & & \\
\hline b2.7 & -0.344538 & Yext1 & 1.3 & 1.7 & 1.7 & & & \\
\hline b2.8 & -0.294118 & Yext2 & 2 & 2.2 & 2.1 & & & \\
\hline b2.9 & -0.907563 & Yext3 & 2.5 & 1.7 & 2 & & & \\
\hline
\end{tabular}

Table 5

Calculation of the level of planning of managers motivation of $\left(Z_{3}\right)$ Level

\begin{tabular}{cccccccccc}
$\begin{array}{c}\text { Model } \\
\text { coefficients }\end{array}$ & Value & $\begin{array}{c}\text { Variable } \\
\text { models }\end{array}$ & \multicolumn{6}{c}{ Value } & \multicolumn{5}{c}{$\begin{array}{c}\text { of planning } \\
\text { of managers' } \\
\text { motivation }\end{array}$} \\
& & & & E1 & E2 & E3 & $\mathbf{Z}_{3}$ & $\mathbf{Z}_{3}^{\prime}$ & $\mathbf{Z}_{3}^{\prime \prime}$ \\
\hline a3 & -0.121212 & $\mathrm{X} 2$ & 2.4 & 2.2 & 1 & & & \\
b3.1 & -0.130952 & Yext1 & 2.6 & 2 & 2.3 & & & \\
b3.2 & 0.206897 & Yext2 & 2.2 & 1.5 & 2.1 & 1 & 1 & 2 \\
b3.3 & -0.18 & Yext3 & 2.1 & 1.5 & 2.1 & & &
\end{tabular}

Table 6

Calculation of the level of organization and regulation of motivation of managers $\left(Z_{4}\right)$ Level

\begin{tabular}{|c|c|c|c|c|c|c|c|c|}
\hline \multirow[t]{2}{*}{$\begin{array}{c}\text { Model } \\
\text { coefficients }\end{array}$} & \multirow[t]{2}{*}{ Value } & \multirow[t]{2}{*}{$\begin{array}{c}\text { Variable } \\
\text { models }\end{array}$} & \multicolumn{3}{|c|}{ Value } & \multicolumn{3}{|c|}{$\begin{array}{l}\text { of organization } \\
\text { and regulation }\end{array}$} \\
\hline & & & E1 & E2 & E3 & $\mathrm{Z}_{4}$ & $Z_{4}^{\prime}$ & $\mathrm{Z}_{4}^{\prime \prime}$ \\
\hline a4 & 0.0178571 & $\mathrm{X} 2$ & 2.3 & 2.5 & 1.2 & & & \\
\hline b4.1 & 0.0357143 & Yint4.1 & 1.4 & 2.1 & 1.7 & & & \\
\hline b4.2 & 0.833333 & Yint4.2 & 1.5 & 1.6 & 1.9 & & & \\
\hline b4.3 & -0.022472 & Yint4.3 & 1.9 & 1.9 & 2 & 2 & 2 & 2 \\
\hline b4.4 & 0.0546624 & Yint4.4 & 2.6 & 2.3 & 2.3 & & & \\
\hline b4.5 & -0.722222 & Yint4.5 & 2.5 & 2.2 & 2 & & & \\
\hline b4.6 & -0.129771 & Yint4.6 & 2.6 & 2.1 & 2 & & & \\
\hline
\end{tabular}

The level of efficiency of managers' work motivation management and conformity of the standard is given in Table
7. If the result obtained does not correspond to the standard, it is assigned a weighting coefficient of 0.1 , if it does - it is assigned the average weighting coefficient between the respective. The sum of the weighting coefficient shall not exceed 1.

Table 7

Calculation of the level of control of the managers' motivation $\left(\mathrm{Z}_{5}\right)$

\begin{tabular}{cccccccccc}
\hline $\begin{array}{c}\text { Model } \\
\text { coefficients }\end{array}$ & Value & $\begin{array}{c}\text { Variable } \\
\text { models }\end{array}$ & Value & \multicolumn{1}{c}{ Control level } \\
& & & E1 & E2 & E3 & $\mathbf{Z}_{5}$ & $\mathbf{Z}_{5}^{\prime}$ & $\mathbf{Z}_{5}{ }^{\prime \prime}$ \\
\hline a5 & -0.136364 & X4 & 2.6 & 2.2 & 2.3 & & & \\
b5.1 & -0.25 & Yext1 & 2 & 1.6 & 2.2 & & & \\
b5.2 & 0.166667 & Yext2 & 2.6 & 2.1 & 1.9 & 1 & 1 & 1 \\
b5.3 & -0.333333 & Yext3 & 2.3 & 2.3 & 1.9 & & &
\end{tabular}

Let us calculate the indicator of the weighted level of managers' work motivation management (Table 8) that characterizes efficiency of management model of managers' work motivation.

Table 8

Calculation of the level of management of motivation of managers

\begin{tabular}{|c|c|c|c|c|c|c|c|c|c|c|c|c|c|}
\hline \multirow[t]{2}{*}{$\dot{0}$} & \multirow[t]{2}{*}{ 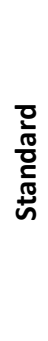 } & \multicolumn{3}{|c|}{ 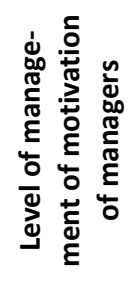 } & \multicolumn{3}{|c|}{ 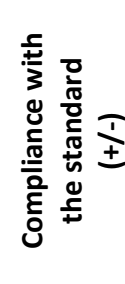 } & \multicolumn{3}{|c|}{ 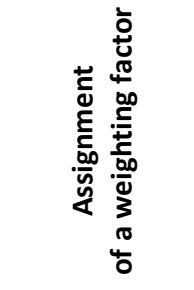 } & \multicolumn{3}{|c|}{ 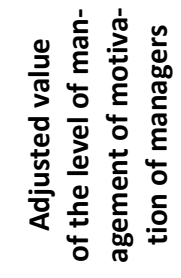 } \\
\hline & & Z & $Z^{\prime}$ & $Z^{\prime \prime}$ & Z & $\mathbf{Z}^{\prime}$ & $Z^{\prime \prime}$ & Z & $\mathbf{Z}^{\prime}$ & $Z^{\prime \prime}$ & Z & $z^{\prime}$ & $Z^{\prime \prime}$ \\
\hline 1 & 1 & 1 & 1 & 2 & + & + & - & 0.35 & 0.6 & 0.1 & 0.35 & 0.6 & 0.2 \\
\hline 2 & 2 & 2 & 3 & 3 & + & - & - & 0.35 & 0.1 & 0.1 & 0.7 & 0.3 & 0.3 \\
\hline 3 & 2 & 1 & 1 & 2 & - & - & + & 0.1 & 0.1 & 0.6 & 0.1 & 0.1 & 1.2 \\
\hline 4 & 1 & 2 & 2 & 2 & - & - & - & 0.1 & 0.1 & 0.1 & 0.2 & 0.2 & 0.2 \\
\hline 5 & 2 & 1 & 1 & 1 & - & - & - & 0.1 & 0.1 & 0.1 & 0.1 & 0.1 & 0.1 \\
\hline $\begin{array}{l}\text { Total } \\
\text { value }\end{array}$ & 6 & 7 & 8 & 10 & $x$ & $x$ & $X$ & 1 & 1 & 1 & 1.45 & 1.3 & 2 \\
\hline
\end{tabular}

According to the consolidated scale (Table 9), we analyze the results obtained according to the accepted levels:

$0-1.2$ - low;

$1.21-2.4$ - medium;

$2.41-3-$ high.

Also, we determine the dynamics (growth/decline) of the results.

Table 9

Determining the level of management motivation of managers and its dynamics

\begin{tabular}{cccccc}
\hline MWM Value & $\begin{array}{c}\text { Comparison } \\
\text { with } \\
\text { accepted } \\
\text { levels }\end{array}$ & $\begin{array}{c}\text { Level } \\
\text { of manage- } \\
\text { ment } \\
\text { motivation } \\
\text { of managers }\end{array}$ & $\begin{array}{c}\text { Absolute } \\
\text { deviation }\end{array}$ & $\begin{array}{c}\text { Relative } \\
\text { devia- } \\
\text { tion }\end{array}$ \\
\hline$Z$ & 1.45 & $1.21-2.4$ & medium & - & - \\
$Z^{\prime}$ & 1.3 & $1.21-2.4$ & medium & -0.15 & -0.11 \\
$Z^{\prime \prime}$ & 2 & $1.21-2.4$ & medium & +0.7 & +0.54 \\
\hline
\end{tabular}


Thus, the results diagnose the medium level of management motivation of managers, but in determining the absolute and relative deviations, we observe both positive and negative dynamics within one level. Because, during the first experiment, at the beginning of the study, it was found that the medium level of management motivation of managers (1.45) during the implementation of the proposed new model of motivation of managers decreased by $11 \%$, although it continued to remain average. However, when re-diagnosing the use of the proposed model of managing the motivation of managers for a long time we revealed an increase in the level of management of motivation of managers by $54 \%$.

For other oil and gas companies, the results of the study of the level of management of managers' work motivation before, during and after the implementation of the management model of managers' work motivation are given in Table 10.

Table 10

Determining the level of management motivation of managers

\begin{tabular}{|c|c|c|c|c|c|c|c|c|c|}
\hline \multirow[t]{2}{*}{ 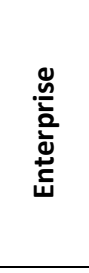 } & \multicolumn{3}{|c|}{$\begin{array}{c}\text { The level } \\
\text { of management } \\
\text { of managers' } \\
\text { work motivation }\end{array}$} & \multicolumn{3}{|c|}{$\begin{array}{c}\text { Comparison } \\
\text { with accepted } \\
\text { levels }\end{array}$} & \multicolumn{3}{|c|}{$\begin{array}{c}\text { Qualitative } \\
\text { assessment } \\
\text { of the level } \\
\text { of management } \\
\text { motivation } \\
\text { of managers }\end{array}$} \\
\hline & Z & $Z^{\prime}$ & $Z^{\prime \prime}$ & Z & $z^{\prime}$ & $Z^{\prime \prime}$ & Z & $\mathbf{Z}^{\prime}$ & $Z^{\prime \prime}$ \\
\hline 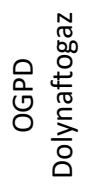 & 1.45 & 1.30 & 2.00 & $\begin{array}{l}1.21 \\
-2.4\end{array}$ & $\begin{array}{l}1.21 \\
-2.4\end{array}$ & $\begin{array}{l}1.21 \\
-2.4\end{array}$ & 衣 & $\frac{\xi}{\frac{\xi}{\partial}}$ & $\frac{\xi}{\stackrel{\xi}{z}}$ \\
\hline 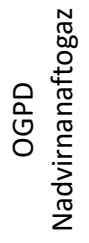 & 1.45 & 1.30 & 1.45 & $\begin{array}{l}1.21 \\
-2.4\end{array}$ & $\begin{array}{l}1.21 \\
-2.4\end{array}$ & $\begin{array}{l}1.21 \\
-2.4\end{array}$ & 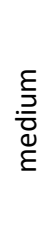 & 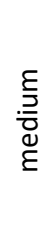 & $\frac{\xi}{\frac{\xi}{\bar{z}}}$ \\
\hline 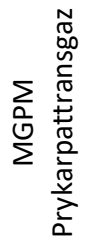 & 1.80 & 1.45 & 2.75 & $\begin{array}{l}1.21 \\
-2.4\end{array}$ & $\begin{array}{c}1.21 \\
-2.4\end{array}$ & $\begin{array}{c}2.41 \\
-3\end{array}$ & 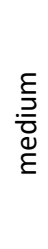 & 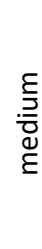 & 点 \\
\hline 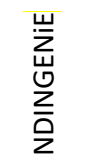 & 1.80 & 1.65 & 2.65 & $\begin{array}{c}1.21 \\
-2.4\end{array}$ & $\begin{array}{l}1.21 \\
-2.4\end{array}$ & $\begin{array}{c}2.41 \\
-3\end{array}$ & $\begin{array}{l}\frac{\xi}{\partial} \\
\frac{\partial}{0} \\
\text { ¿ } \\
\varepsilon\end{array}$ & $\frac{\xi}{\underline{z}}$ & 点 \\
\hline
\end{tabular}

At the same time, as a result of the introduction of the management model of managers' work motivation at MGPM "Prykarpattransgaz" and in NDINGENiE a high level of management of managers' work motivation was achieved, which amounted to 2.75 and 2.65 points, respectively. It should be noted that the implementation of the model of managing the motivation of managers at OGPD "Nadvirnanaftogaz" did not give a significant result, due to the limitation of the cost of motivation and remuneration of managers.

Based on the generalization of the results of expert evaluation of the system of equations solution, it was established that the level of analysis and goal setting increased from low to medium, the level of development and making management decisions increased from medium to high, the level of planning increased from low to high for OGPD "Dolynaftogaz", which led to increase of management level of managers' work motivation by 0.54 ( $+54 \%)$, and in absolute terms - from 1.45 to 2.0. Positive results from the implementation of the management model of managers' work motivation were obtained at other surveyed enterprises. It should be noted that for MGPM "Prykarpattransgaz" and NDINGENiE the level of management of work motivation has increased to high, which indicates the effectiveness and feasibility of implementing a model of management of managers' work motivation at oil and gas enterprises.

\section{CONCLUSIONS}

Based on the analysis of the essence of the managerial work of managers model, the following principles of building a management model of motivation of managers have beeb defined:

1) systematicity,

2) goal orientation,

3) incentives,

4) continuity,

5) reliability,

6) unity of action,

7) elasticity

8) innovativeness,

9) resource security,

10) cost-effectiveness,

11) complexity,

12) balance of interests - which determine the basic functions of the management model of motivation of managers:

a) goal setting,

b) assessment and forecasting of the state and efficiency,

c) development and decision making,

d) planning,

e) organizational,

f) communication and subordination,

g) regulation of the management model of motivation of managers,

h) control.

The structural and logical scheme of the MMMWM has been developed, which:

1) visualizes its structuring in three blocks: motivational, organizational, functional;

2) ensures the implementation of certain 12 principles of its effective construction (consistency, target orientation, incentives, continuity of development, reliability, unity of action, elasticity, innovation, security, efficiency, complexity, balance of interests);

3) regulates the implementation of the principles in the basic functions of the MMMWM to motivate the work of managers (goal setting, assessment and forecasting of the state and efficiency, development and decision- 
making, planning, organizational, communication and subordination, regulation of the functioning of the MMMWM, control;

4) reflects the interaction of the subject and the object in the process of formation and implementation of the system of managers' work motivation at the enterprise. Factors that are divided into external and internal motivators of management of managers' work motivation have been formed.

The management model of managers' work motivation which is presented by the following subsystems is offered: "X" - target subsystem (the management process of managers' work motivation), "Y" - providing subsystem (factors of rational achievement of the goals), "XY" - providing subsystem (regulatory legal acts, resources), "Z" - management subsystem (reflects the implementation of the general functions of management work motivation on the basis of experience), which are characterized by parameters, indicators, criteria for managing the motivation of managers. According to the method of linear multiple regression, a system of equations was constructed to describe the economic-mathematical model of management motivation at oil and gas enterprises, which after the repeated experiments provided diagnostics of indicators before, during and after the implementation of management motivation model. Based on the processing of the results of expert evaluation and the use of the solution of the system of equations, the level of analysis and goal setting was found to be from low to medium, the level of development and management decisions - from medium to high, the level of planning - from low to high for OGPD "Dolynaftogaz" which led to an increase in the level of management of managers' motivation by $0.54(+54 \%)$, and in absolute terms - from 1.45 to 2.0. Positive results from the implementation of the model of management motivation of managers were obtained at other surveyed enterprises, and for MGPM "Prykarpattransgaz" and NDINGENiE the level of management of work motivation increased to high, which indicates the effectiveness and feasibility of management motivation of managers at oil and gas enterprises.

\section{REFERENCES}

[1] Z. Smirnova, O. Vaganova, S. Sirotyk, D. Sidorova, J. Klyueva, E. Chelnokova, M. Mukhina. (2019). "Improving the personnel motivation system in service activities organizations". International Journal of Innovative Technology and Exploring Engineering, 8(12), pp. 5056-5059. Available: https://DOI:10.35940/ijitee.K2464.1081219

[2] I. Kinash, U. Andrusiv, O. Golovnia, I. Popadynets. (2019). "Aspects of the formation and development of innovation infrastructure in Ukraine". Management Science Letters. 9(13), pp. 2403-2414.

[3] M. Gunduz and E. Abdi, (2020). "Motivational factors and challenges of cooperative partnerships between contractors in the construction industry". Journal of Management in Engineering. 36(4). Available: https:// DOI:10.1061/(ASCE)ME.1943-5479.0000773
[4] M. Dogar. (2019). "Breach of psychological contract: Impact on workforce motivation and organizational sustainability". Emerald Emerging Markets Case Studies. 9(4), pp. 1-20. Available: https://DOI:10.1108/EEMCS-01-20190005

[5] S. Lorincová P. Štarchoň, D. Weberová, M. Hitka, M. Lipoldová. (2019). "Employee motivation as a tool to achieve sustainability of business processes". Sustainability (Switzerland). 11(13) Available: https://DOI:10.3390/su11133509

[6] A. Cherchata, I. Popovychenko, U. Andrusiv, L. Simkiv, O. Kliukha, O. Horai. (2020). "A methodology for analysis and assessment of business processes of Ukrainian enterprises". Management Science Letters. 10(3), pp. 631-640. Available: https://DOI:10.5267/j.msl.2019.9.016

[7] A. Bryson, M. White. (2019). "HRM and small-firm employee motivation: Before and after the great recession". ILR Review, 72(3), pp. 749-773. Available: https://DOI:10.1177/0019793918774524

[8] R. Kampf, M. Hitka, M. Potkany. (2014). “Interannual differences in employee motivation in manufacturing enterprises in Slovakia". Communications - Scientific Letters of the University of Zilina. 16(4), pp. 98-102.

[9] R. Kampf, S. Lorincova, L. Kapustina, L. Lizbetinova. (2017). "Motivation level and its comparison between senior managers and blue-collar workers in small and medium-sized transport enterprises". Communications - Scientific Letters of the University of Zilina. 19(4), pp. 43-49.

[10] M. Mikkelsen, C. Jacobsen, L. Andersen. (2017). “Managing employee motivation: Exploring the connections between managers' enforcement actions, employee perceptions, and employee intrinsic motivation". International Public Management Journal. 20(2), pp. 183-205. Available: https://DOI:10.1080/10967494.2015.1043166

[11] M. Hitka, D. Weberova, L. Ližbetinova, M. Vertáková. (2017). "Comparison of the motivation level of manufacturing enterprises employees in V4 countries". Paper presented at the Proceedings of the $30^{\text {th }}$ International Business Information Management Association Conference, IBIMA 2017 - Vision 2020: Sustainable Economic Development, Innovation Management, and Global Growth, 2017Jan

[12] K. Pakovska, M. Ballarin, M. Vanek, J. Chlopecky. (2015). "Influence of motivation on work performance and loyalty of employees in industrial enterprises". Paper presented at the International Multidisciplinary Scientific GeoConference Surveying Geology and Mining Ecology Management. SGEM, 3(1) pp. 399-406.

[13] T. Du. (2013). "Study on theory framework of enterprise strategic motivation". Paper presented at the $19^{\text {th }}$ International Conference on Industrial Engineering and Engineering Management: Engineering Economics Management, pp. 633-641. Available: https://DOI:10.1007/978-3-64238442-4_67

[14] V. levdokymov, S. Lehenchuk, D. Zakharov, U. Andrusiv, O. Usatenko, L. Kovalenko. (2020). "Social capital measurement based on "The value explorer" method". Management Science Letters, 10(6), 1161-1168. Available: https://DOI:10.5267/j.msl.2019.12.002

[15] A. Panagiotakopoulos. (2013). "The impact of employee learning on staff motivation in greek small firms: The employees' perspective". Development and Learning in Organisations, 27(2), pp. 13-15. Available: https://DOI:10.1108/14777281311302030 
[16] U. Andrusiv, L. Simkiv, O. Dovgal, N. Demchuk, N. Potryvaieva, A. Cherchata, I. Popadynets, G. Tkachenko, O. Serhieieva, H. Sydor. (2020). „Analysis of economic development of Ukraine regions based on taxonomy method". Management Science Letters. vol. 10, no. 3, pp. 515-522. Available: https://DOI:10.5267/j.msl.2019.9.029

[17] A. Polyanska, I. Zapukhliak, O. Diuk. (2019). “Culture of organization in conditions of changes as an ability of efficient transformations: The case of gas transportation companies in Ukraine". Oeconomia Copernicana. 10(3), pp. 561580. Available: https://DOI:10.24136/oc.2019.027

[18] M. Dykha, Y. Cheban, O. Bilyk, Z. Siryk, O. Khytra, A. Dudnyk. (2020). "Management of corporate social activity in the organization". International Journal of Management, 11(5), pp. 97-107. Available: https://DOI:10.34218/IJM.11.5.2020.010

[19] O. Khytrova, I. Sysoieva, H. Dolha, V. Peniuk, O. Motuzenko. (2020). "Ensuring the growth of enterprises and organizations through the motivation of managerial staff". International Journal of Economics and Business Administration, 8(2), pp. 219-228. Available: https://DOI:10.35808/ijeba/454

[20] M. Buble, A. Juras, I. Matić. (2014). "The relationship between managers' leadership styles and motivation". Management (Croatia), 19(1), pp. 161-193.

[21] L. Paglis, S. Green. (2002). "Leadership self-efficacy and managers' motivation for leading change". Journal of Organizational Behavior, 23(2), pp. 215-235. Available: https://DOI:10.1002/job.137

[22] M. Mast, J. Hall, P. Schmid. (2010). "Wanting to be boss and wanting to be subordinate: Effects on performance motivation". Journal of Applied Social Psychology, 40(2), pp. 458-472. Available: https://DOI:10.1111/j.15591816.2009.00582.x

\section{Iryna Popadinets}

ORCID ID: 0000-0003-0456-827X

Vasyl Stefanyk Precarpathian National University

Department of Management

and Business Administration

Shevchenka St, 57, Ivano-Frankivsk, Ukraine

e-mail: irav.if@gmail.com

\section{Uliana Andrusiv}

ORCID ID: 0000-0003-1793-0936

Ivano-Frankivsk National Technical University Oil and Gas Department of Theory of Economics and Management Karpatska St., 15, 76019, Ivano-Frankivsk, Ukraine e-mail: andrusivu@ukr.net

\section{Olga Galtsova}

ORCID ID: 0000-0003-0012-0371

Classical Private University, Zaporizhzhia

Head of the Department of National Economy

Marketing and International Economic Relations 70B, Zhukovskogo str., 69002 Zaporizhzhya, Ukraine e-mail: galtsova_o@ukr.net
[23] A. Wziatek-Staśko. (2016). "The extent of managers' motivation as a determinant of leadership quality". Engineering Management in Production and Services. 8(1), pp. 37-46. Available: https://DOI:10.1515/emj-2016-0004

[24] A. Zhuplev, D. Shtykhno. (2009). "Motivations and obstacles for small business entrepreneurship in Russia: Fifteen years in transition". Journal of East-West Business, 15(1), pp. 25-49. Available: https://DOI:10.1080/10669860902900347

[25] A. Zhuplev, A. Kon'Kov, F. Kiesner. (1998). "Russian and American small business: Motivations and obstacles". European Management Journal, 16(4), pp. 505-516. Available: https://DOI:10.1016/S0263-2373(98)00027-9

[26] I. Popadynets, U. Andrusiv, M. Shtohryn, O. Galtsova. (2020). "The effect of cooperation between universities and stakeholders: Evidence from Ukraine". International Journal of Data and Network Science. 4(2), pp. 199-212. Available: https://DOI:10.5267/j.ijdns.2020.1.001.

[27] U. Andrusiv, O. Galtsova. (2017). "Evaluation of innovation activity of construction enterprises". Scientific bulletin of Polissia. 3(11), P.1, pp. 204-215 Available: https://DOI:10.25140/2410-9576-2017-1-3(11)-204-215.

[28] H. Zelinska, U. Andrusiv, L. Simkiv. (2020). "Knowledge economy: Trends in the world and analysis of Ukraine". Journal of Eastern European and Central Asian Research. 7(1), pp. 104-113. Available: https://DOI:10.15549/jeecar.v7i1.325

\author{
Mariia Bahorka \\ ORCID ID: 0000-0002-8500-0362 \\ Dnipro State Agrarian and Economics University \\ Head of the Department of Marketing \\ 25, Voroshylova str., Dnipro \\ Dnipropetrovsk, 49027, Ukraine \\ e-mail: olena_dovgal@ukr.net \\ Natalia Yurchenko \\ ORCID ID: 0000-0002-3156-6790 \\ Dnipro State Agrarian and Economics University \\ 25, Voroshylova str., Dnipro \\ Dnipropetrovsk, 49027, Ukraine \\ e-mail: natalia_ivanivn@ukr.net
}

